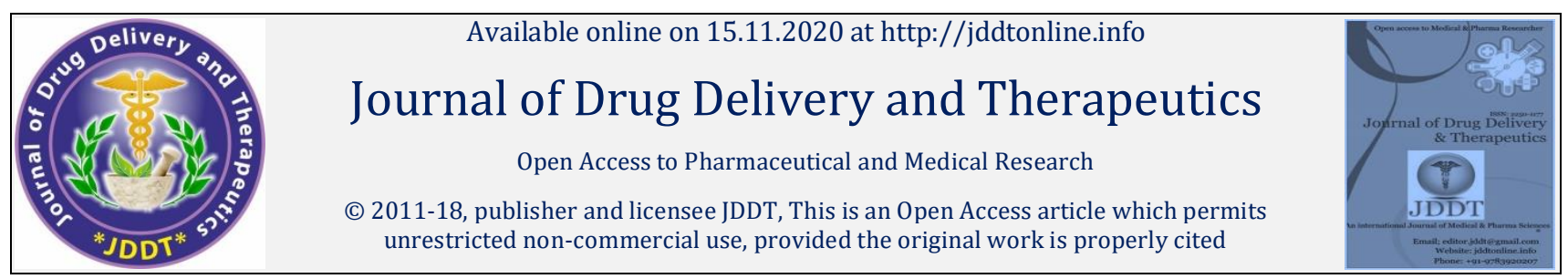

Open $\odot$ Access

Review Article

\title{
A Review on Pediatric Adverse Effects of First Line Anti-Tubercular Drugs
}

\author{
B Athulnadh, K. Sreejith*, K.V. Musaina Thasneem, Namitha Maniyan, P.P. Muhamed Faris, Cherakkulath
} C Neena

Department of Pharmacy Practice, College of Pharmaceutical Sciences, Government Medical College, Kozhikode, Kerala, 673008, India

\begin{abstract}
Tuberculosis is a potentially serious communicable disease caused by mycobacterium tuberculosis. That mainly affects lungs. Tricky mitigation and diagnosis cause the childhood tuberculosis a growing burden for society. Directly Observed Treatment Short course (DOTS) strategy is one of the largest public health programmes found to be beneficial against tuberculosis. Anti-tubercular treatment shows greater level of efficacy high degree of toxicity; however combination treatment, especially during the intensive phase of therapy may produce severe adverse events. First line therapy of Tuberculosis leads to serious adverse effects. Serious adverse effects are less in children receiving drug therapy. Major adverse event associated with anti TB drugs is hepatotoxicity.
\end{abstract}

Keywords: Tuberculosis, DOTS, isoniazid, rifampicin, pyrazinamide, ethambutol and streptomycin

Article Info: Received 02 Sep 2020; $\quad$ Review Completed 16 Oct 2020; $\quad$ Accepted 24 Oct 2020; Available online 15 Nov 2020

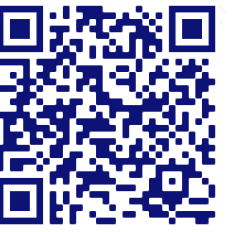

Cite this article as:

Athulnadh B, Sreejith K, Thasneem KVM, Maniyan N, Faris PPM, Neena CC, A Review on Pediatric Adverse Effects of First Line Anti-Tubercular Drugs, Journal of Drug Delivery and Therapeutics. 2020; 10(6):216-218

http://dx.doi.org/10.22270/jddt.v10i6.4544

*Address for Correspondence:

K. Sreejith, Assistant Professor of Pharmacy, College of Pharmaceutical Sciences, Government Medical College, Kozhikode, Kerala, 673008, India

\section{INTRODUCTION}

Tuberculosis is an infection caused by bacteria mycobacterium tuberculosis complex. In 1993 world health organization declared Tuberculosis as a medical emergency. There are two types of tuberculosis TB disease and latent TB infection .TB disease patients have active TB germs. They have symptoms and spread germs to others. Latent TB infection patients are asymptomatic and do not transmit germs to others. ${ }^{1}$

Tuberculosis in children is a one of the major problem. Children can have tuberculosis at any age. Most commonly between 1 and 4 Diagnosis is difficult in childhood tuberculosis .Symptoms are varied and non-specific. DOTS (directly observed treatment short course) is the therapy recommended by WHO for tuberculosis. The duration of therapy is about 6-8 months. It includes therapy with the first line drugs and second line drugs. First lines drugs include isoniazid, rifampicin, pyrazinamide, ethambutol and streptomycin. ${ }^{2}$

\section{PRINCIPLES OF TUBERCULOSIS TREATMENT IN CHILDREN}

Treatment goals of Tuberculosis in children and adults are same.

The important goals are:

1. Patient cure

2. To reduce death from Tuberculosis disease

3. Prevention of relapse of Tuberculosis

4. Prevention of development and spread of drugresistant Tuberculosis

5. Reduce spread of tuberculosis

6. Achieve all this with minimal toxicity to the patients. 4

The following are the doses of anti-tubercular drugs used for the treatment of TB in children daily:

$10 \mathrm{mg} / \mathrm{kg}$ (range $7-15 \mathrm{mg} / \mathrm{kg}$ ) of Isoniazid $(\mathrm{H})$ : A maximum of $300 \mathrm{mg} /$ day

$15 \mathrm{mg} / \mathrm{kg}$ (range 10-20 mg/kg) of Rifampicin(R): maximum dose of $600 \mathrm{mg} /$ day 
$35 \mathrm{mg} / \mathrm{kg}$ of pyrazinamide (Z) (range $30-40 \mathrm{mg} / \mathrm{kg}$ )

$20 \mathrm{mg} / \mathrm{kg}$ of Ethambutol (E) (range 15-25 mg/kg)

Children who are at a chance to have pulmonary tuberculosis and live in a society with reduced chance to occur HIV and children who are not HIV-positive can be treated first for 2 months with a three-drug regimen (HRZ) ,then for 4 months by a two-drug (HR) regimen at the following doses:

$10 \mathrm{mg} / \mathrm{kg}$ (range $10-15 \mathrm{mg} / \mathrm{kg}$ ) of Isoniazid (H): A maximum dose of $300 \mathrm{mg} /$ day

$15 \mathrm{mg} / \mathrm{kg}$ (range 10-20 mg/kg) of Rifampicin (R): A maximum dose of $600 \mathrm{mg} /$ day

$35 \mathrm{mg} / \mathrm{kg}(30-40 \mathrm{mg} / \mathrm{kg}$ ) of Pyrazinamide (Z)

In case of children with pulmonary tuberculosis, Streptomycin cannot be used as a first-line drug. ${ }^{3}$

Isoniazid $(\mathrm{H})$

The major adverse reactions of isoniazid are neurologic and hepatic but both these are less in children. The isoniazid level in the body at any given dose in adults and children is based on the extend of acetylation. Hepatitis is one of serious adverse reaction of isoniazid. Jaundice is also reported in some children. The child may feel sick, constipation, difficulty in passing urine; get tingling or numbness in the hands or feet. 1

Neurologic side effects are mainly dose related and that includes peripheral neuropathy, ataxia and paraesthesia. The competition of isoniazid with vitamin B6 (pyridoxine) is the reason for neurologic side effects. Children have less chance to cause pyridoxine deficiency with isoniazid when compared to adults. Hypersensitivity reactions include fever, skin eruptions toxic epidermal necrolysis. Haematological reactions include Agranulocytosis, aplastic anemia, thrombocytopenia, and eosinophilia. ${ }^{1}$

Elimination of isoniazid is depending on age. Younger children can eliminate INH faster than older children and adults. This is because; in young children there is larger liver size in proportion to total body weight. ${ }^{4}$

The malnutrition can cause pathophysiological changes in children and which can alter pharmacokinetics, response of drug and may lead to toxicity. 5

\section{Rifampicin (R)}

Rifampicin is a well-tolerated drug. It causes allergic and hepatotoxic side effects. Allergic side effects include fever, eosinophilia, rashes, flu-like syndrome, kidney disease with acute renal insufficiency and haemolytic anaemia. These side effects occur commonly in adults with intermittent, highdose intake and with increasing age. The occurrence of hepatotoxicity in children using rifampicin alone is found to rare. Using rifampicin and isoniazid for the treatment of TB may develop hepatotoxic reactions. 6

Children prescribed with $10 \mathrm{mg} / \mathrm{kg}$ body weight of Rifampicin have less concentration of drug when compared to adults who receive the same dose of drug. When rifampicin and ethambutol are administered together decreased rifampicin exposure are seen, though it's not significant. Malnutrition in adults reduces the capacity of rifampicin to bind to proteins, and increase the renal elimination and reduce level of drug in adults. 6

\section{Pyrazinamide (Z)}

Most commonly pyrazinamide is used in combination therapy with other drugs. In active TB disease it is used for two months of therapy. The common side effects include gastrointestinal side effects, hepatotoxicity, non-gouty polyarthralgia and gouty arthritis. Other side effects are child's skin may become more sensitive to sun light, stomach upset, and headache, feel dizzy, trouble sleeping. A small raise in plasma concentration of uric acid is also reported in some cases.

It was found that Pyrazinamide and Ethambutol have lower plasma levels of drug and shorter half-lives in children than in adults, and have recommended an increase in the dose for children. Children who are underweight have lower peak concentration of Rifampicin and Pyrazinamide when compared to normal children. 6

There is no significantl reduction in Pyrazinamide and Ethambutol concentrations in HIV infected children when compared to the uninfected. 7

\section{Ethambutol (E)}

In TB endemic countries Usage of ethambutol in young children is high. The serious adverse effect associated with Ethambutol is retrobulbar neuritis,it can be reversed if identified early. On opthalmoloscopic examination, the fundus appears to be normal because the neuritis is retrobulbar in nature. The marks of toxicity are loss of visual acuity and colour vision. These indications may be slow in young children. Other side effects include stomach upset,cramps, diarrhoea and metallic taste. The child may develop itchiness or rash. Thiacetazone cause severe Stevens-Johnson reactions in HIV-infected adults and children.So,Ethambutol was introduced to replace Thiacetazone. The incidence of eye toxicity depends on dose and duration of therapy. In adults, there is an increased chance for eye toxicity among patients with lower concentrations of Zinc. Tuberculosis infected children, especially having HIV/AIDS are very likely to cause zinc deficiency. There is no evidence on whether HIV infection increases the risk of ethambutol toxicity. Some other rare adverse effect of ethambutol include Blurred vision, pain in the eye, red-green color blindness,loss of vision, fever, joint pain, numbness, tingling, burning pain,weakness in hands or feet, skin rashes. ${ }^{9}$

\section{Streptomycin}

Dose related toxic effects are seen in the case of streptomycin and inherent to aminoglycoside antibiotics. The adverse effects are otovestibular toxicity; it can lead to permanent loss of hearing, and nephrotoxicity which is less in case of children. Other adverse effects are stomach upset, nausea, vomiting, loss of appetite, spinning sensation, rash fever, edema etc. Because of serious adverse effect associated with streptomycin its usage in children are limited. Streptomycin produces renal side effects due to their accumulation in the renal tubules. But these are more common in elderly individuals than in children. Immediately after the administration of streptomycin it can cause perioral paraesthesia. This adverse effect is benign. 10 


\section{APROACH TO CONTROL SIDE EFFECTS OF THE MOST COMMON ANTI- TB DRUGS}

\begin{tabular}{|l|l|l|}
\hline Side Effects & Causative Drug & Control \\
\hline Skin rashes & Streptomycin,rifampicin,pyrazinamide,isoniazid & Discontinuation of drugs \\
\hline Hearing loss & Streptomycin & Discontinuation of drug \\
\hline Confusion & Most of anti TB drugs & Discontinue the drug \\
\hline Visual disorders & Ethambutol & Discontinue the drug \\
\hline Shock, acute kidney disease & Rifampicin & Discontinue rifampicin \\
\hline Jaundice & Rifampicin, isoniazid and pyrazinamide & Discontinue anti TB drugs \\
\hline Oliguria & Streptomycin & Discontinue streptomycin \\
\hline
\end{tabular}

\section{CONCLUSION}

Tuberculosis is an infection caused by bacteria mycobacterium tuberculosis complex. . There are two types of tuberculosis TB disease and latent TB infection .Treatment of tuberculosis in children using variety of combination therapy regimens shows that anti-TB drugs are well tolerated at currently prescribed doses. Serious adverse effects are less in children. Major adverse event associated with anti TB drugs is hepatotoxicity. The occurrence of hepatotoxicity in children using rifampicin (R) alone is rare. Because of serious adverse effect associated with streptomycin its usage in children are limited.

\section{REFERENCES}

1. World Health Organization. Rapid advice: treatment of tuberculosis in children. Geneva: World Health Organization; 2010.

2. Frydenberg AR, Graham SM. Toxicity of first-line drugs for treatment of tuberculosis in children. Tropical Medicine \& International Health. 2009 Nov; 14(11):1329-37.

3. World Health Organization. Guidance for national tuberculosis programmes on the management of tuberculosis in children. World Health Organization; 2014.

4. Thee S, Seddon JA, Donald PR, Seifart HI, Werely CJ, Hesseling AC, Rosenkranz B, Roll S, Magdorf K, Schaaf HS. Pharmacokinetics of isoniazid, rifampin, and pyrazinamide in children younger than two years of age with tuberculosis: evidence for implementation of revised World Health Organization recommendations. Antimicrobial agents and chemotherapy. 2011 Dec 1; 55(12):5560-7.

5. Ramachandran G, Kumar AH, Bhavani PK, Gangadevi NP, Sekar L, Vijayasekaran D, Rekha VB, Kumar SR, Ravichandran N, Mathevan G, Swaminathan S. Age, nutritional status and INH acetylator status affect pharmacokinetics of antituberculosis drugs in children. INT J TUBERC LUNG DIS. 2013; 17(6):800-6.

6. Ramachandran G, Kumar AH, Swaminathan S. Pharmacokinetics of anti-tuberculosis drugs in children. The Indian Journal of Pediatrics. 2011 Apr 1; 78(4):435-42.

7. Graham SM, Bell DJ, Nyirongo S, Hartkoorn R, Ward SA, Molyneux EM. Low levels of pyrazinamide and ethambutol in children with tuberculosis and impact of age, nutritional status, and human immunodeficiency virus infection. Antimicrob Agents Chemother. 2006; 50:407-13.

8. Al-Dossary FS, Ong LT, Correa AG \& Starke JR, Treatment of childhood tuberculosis with a six month directly observed regimen of only two weeks of daily therapy. Pediatric Infectious Disease Journal 2002; 21:91-97.

9. Frydenberg A, Graham S. What are the major antituberculous drug toxicities in children?.

10. Arbex MA, Varella MD, Siqueira HD, Mello FA. Antituberculosis drugs: drug interactions, adverse effects, and use in special situations. Part 2: second line drugs. J Bras Pneumol. 2010 Jun; 36(5):641-56.

11. Corrigan D \& Paton J, Hepatic enzyme abnormalities in children on triple therapy for tuberculosis. Pediatric Pulmonology 1999; 27:37-42.

12. Sterling TR, Bethel J, Goldberg S, Weinfurter P, Yun L, Horsburgh CR, Tuberculosis Epidemiologic Studies Consortium. The scope and impact of treatment of latent tuberculosis infection in the United States and Canada. American journal of respiratory and critical care medicine. 2006 Apr 15; 173(8):927-31.

13. Gideon HP, Flynn JL. Latent tuberculosis: what the host "sees"?. Immunologic research. 2011 Aug 1; 50(2-3):202-12.

14. Kabra SK, Lodha R, Seth V. Category based treatment of tuberculosis in children. Indian Pediatr. 2004 Sep; 41(9):92737.

15. Sharma S, Sarin R, Khalid UK, Singla N, Sharma PP, Behera D. The DOTS strategy for treatment of paediatric pulmonary tuberculosis in South Delhi, India. The international journal of tuberculosis and lung disease. 2008 Jan 1; 12(1):74-80.

16. Arora VK, Gupta R. Directly observed treatment for tuberculosis. The Indian Journal of Pediatrics. 2003 Nov 1; 70(11):885-9.

17. Chauhan LS, Arora VK, Central TB, Directorate General of Health Services M. Management of pediatric tuberculosis under the Revised National Tuberculosis Control Program (RNTCP). Indian pediatrics. 2004 Sep; 41(9):901.

18. Al-Dossary FS, Ong LT, Correa AG, Starke JR. Treatment of childhood tuberculosis with a six month directly observed regimen of only two weeks of daily therapy. The Pediatric infectious disease journal. 2002 Feb 1; 21(2):91-7.

19. Schaaf HS, Thee S, van der Laan L, Hesseling AC, Garcia-Prats AJ. Adverse effects of oral second-line antituberculosis drugs in children. Expert opinion on drug safety. 2016 Oct 2; 15(10):1369-81. 